\title{
Isotope fractionation of Fe by hypervelocity impacts evidenced by Australasian microtektites
}

STEPAN M. CHERNONOZHKIN ${ }^{1}$, CLAUDIA GONZÁLEZ DE VEGA ${ }^{1}$, NATALIA ARTEMIEVA ${ }^{2}$, BASTIEN SOENS ${ }^{3}$, JOKE BELZA $^{1}$, EDUARDO BOLEA FERNANDEZ ${ }^{1}$, MATTHIAS VAN GINNEKEN ${ }^{4}$, BILLY P. GLASS ${ }^{5}$, LUIGI FOLCO $^{6}$, MATTHEW J. GENGE ${ }^{7}$, PHILIPPE CLAEYS ${ }^{3}$, FRANK VANHAECKE ${ }^{8}$ AND STEVEN GODERIS ${ }^{3}$

${ }^{1}$ University Ghent

${ }^{2}$ Planetary Science Institute

${ }^{3}$ Vrije Universiteit Brussel

${ }^{4}$ University of Kent

${ }^{5}$ University of Delaware

${ }^{6}$ CISUP, Università di Pisa

${ }^{7}$ Imperial College London

${ }^{8}$ Ghent University

Presenting Author: Stepan.Chernonozhkin@UGent.be

Evaporation and condensation, together with the associated fractionation effects, have been fundamental in governing the current elemental and isotopic composition of the Solar System. Although isotope fractionation of moderately volatile elements (e.g. $\mathrm{Cu}, \mathrm{Zn}, \mathrm{Sn}$ ) has been observed in tektites due to impact heating $[1,2]$, the exact nature of the processes leading to this fractionation during hypervelocity impacts remains poorly understood. By studying the $\mathrm{Fe}$ isotopic composition in situ using laser ablation multi-collector ICP-MS in a set of 48 microtektites collected across the Australasian strewn field from the South China Sea to Antarctica [3,4], we observed $\delta^{56 / 54} \mathrm{Fe}$ values spanning over nearly 5\%. This range is especially unexpected as macroscopic tektites do not show variation of the $\mathrm{Fe}$ isotopic composition within the measurement uncertainty. This finding demonstrates that impact events do not simply lead to melting, melt expulsion and evaporation, but involve a convoluted sequence of processes during the impact event, which include evaporation, condensation, and variable degrees of mixing between isotopically heavy and light Fe reservoirs. These isotope fractionation processes are followed by ablative evaporation during atmospheric re-entry for the collection sites most remote from the impact site. Hypervelocity impacts can, as such, not only generate isotopically heavy, but also isotopically light ejecta, with isotope ratio variations for more volatile elements likely even larger than those observed for Fe [5]. The mechanisms demonstrated here apply to all solid planetary surfaces in the Solar System and call for a revision of our understanding of the effects of impact processing on the isotopic evolution of planetary crusts.

[1] Rodovská et al. (2017) Meteorit. Planet. Sci. 52, 2178 2192. [2] Creech et al. (2019) Chem. Geol. 528, 119279. [3] Folco et al. (2016) Polar Sci. 10, 147-159. [4] Soens et al. (2021) Geosci. Front. 12, 101153. [5] Herzog et al. (2008) Meteorit. Planet. Sci. 43, 1641-1657. 